\title{
A study of the proficiency and performance of Iranian Air Traffic Controllers: attitude, work experience and specific aviation English courses
}

\author{
Massoud Rahmati and Siros Izadpanah* (D)
}

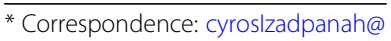
yahoo.com

Department of English Language Teaching, Zanjan Branch, Islamic Azad University, Zanjan, Iran

\begin{abstract}
This study is an exploratory study, which was conducted in relation to the study of the proficiency and performance of Iranian Air Traffic Controllers: attitude, work experience, and specific Aviation English courses. Few studies have been conducted in this field. The Aviation English Courses in Iran are very similar to Content-Based Language Training (CBLT) courses. To this end, the participants were 278 Iranian ATCOs who were selected from 1000 Iranian ATCOs based on Cochran formula. The instrument was designed by the European organization for the safety of air navigation. For data to be analyzed in this study, software SPSS 24.0, AMOS 23.0, structural equation model (SEM), path analysis model, and confirmatory factor analysis (CFA) have been used. According to the main findings of this research based on its research hypotheses, firstly, the Iranian ATCOs' performance had a significant positive effect on proficiency. But in the effect of performance on proficiency, work experience did not have a positive moderating role and passing CBLT courses had a positive moderating role. Secondly, Iranian ATCOs' work experience and passing CBLT courses in the effect of attitude on proficiency had not a good mediator. The results of this research can be used to improve the aviation English training in Iran Airports and Air Navigation Company.
\end{abstract}

Keywords: ATCOs, Aviation English, Performance, Proficiency, Work experience

\section{Introduction}

The English language was chosen by the ICAO since 1951 as an official language of aviation, the United Nations (UN) agency are answerable for air navigation in areas of responsibility (Borowska, 2018). Even, the most experienced ATCOs and pilots have difficulty prevailing the challenge of communication during international operation. Poor ATC-pilot communications is a significant problem in the aviation industry, as it can be connected to over $70 \%$ of aviation incidents (Barshi \& Healy, 2002; Bolton \& Pan, 2018; Connell, 1996).

(c) The Author(s). 2021 Open Access This article is licensed under a Creative Commons Attribution 4.0 International License, which permits use, sharing, adaptation, distribution and reproduction in any medium or format, as long as you give appropriate credit to the original author(s) and the source, provide a link to the Creative Commons licence, and indicate if changes were made. The images or other third party material in this article are included in the article's Creative Commons licence, unless indicated otherwise in a credit line to the material. If material is not included in the article's Creative Commons licence and your intended use is not permitted by statutory regulation or exceeds the permitted use, you will need to obtain permission directly from the copyright holder. To view a copy of this licence, visit http://creativecommons.org/licenses/by/4.0/. 
Aviation English is separated into two different periods. One time before the ICAO 2003 announcement, and one after that date. ICAO said in an announcement that all member states' pilots and ATCOs must attain a level 4 (Garcia, 2015). ICAO was designed 5 March 2008, as a deadline for Contracting States aviation professionals, to achieve the minimum language proficiency level assigned by ICAO. Nevertheless, since some States were not in accordance with these requirements by 2008, ICAO determined to expand the deadline to 5 March 2011 (ICAO, 2004). Before the reception of establishing Language Proficiency Standards and Recommended Practices by the ICAO Council in 2003, English language training for ATCOs' or pilots was planned according to the organization's budget. The 2008 ICAO language testing Standards and Recommended Practices (SARPs) changes the context of how English language training (Mathews, 2007; Williams, 2016). The goal of this is to reduce communication difficulties by standardizing skill levels for ATCOs' and pilots (Baldursson, 2017; Borowska, 2018; Gardilcic, 2003; Khruawan \& Dennis, 2017; Moder \& Halleck, 2009, Moriyoshi, 2010;Tajima, 2004).

English is widely used in Iran. In addition, Iranian ATCOs read general English lessons and special aviation courses. Moreover, Iranian ATCOs need to have great aviation English proficiency and performance to be able to work in international circumstances. The aviation educational system requires different studies on the assessment, personnel attitudes, performance, proficiency, and etc. Therefore, in order to fill the gap, different research has been done on various aspects of aviation English. Accordingly, the aim of this research was to survey the following research hypotheses: 1) the performance has a significant positive effect on the proficiency of individuals. 2) In the effect of performance on proficiency, work experience has a positive moderating role.3) in the effect of performance on proficiency, passing aviation English courses (CBLT courses) has a positive moderating role.4) in the effect of attitude on proficiency, work experience had a positive moderating role. 5) In the effect of attitude on proficiency, passing aviation English courses (CBLT courses) has a positive moderating role.

\section{Literature review}

The inadequate language skills of ATCOs and pilots in civil aviation history have been one of the participating factors affecting various accidents and incidents (ICAO, 2010). As it mentioned by Kim and Elder (2014, p.133), "a single piece of unclarified information could have disastrous results in air traffic control". ICAO was designed 5 March 2008(extended until 2011), as a deadline for Contracting States aviation professionals, to achieve the minimum language proficiency level assigned by ICAO (ICAO, 2004). Therefore, March 2011, ICAO presented new language proficiency requirements (LPRs) to set guidelines for international aviation communication. The goal of this was to reduce communication difficulties by standardizing skill levels for ATCOs' and pilots (Baldursson, 2017; Borowska, 2018; Gardilcic, 2003; Tajima, 2004; Trippe 2018; Waltz \& Bausell 1981).

Aviation English is taught for specific purpose trainees that are either students or speakers in working situations (Rothaug, 2004, Authority, C. A., 2010; Zolfagharian, 2017). The ICAO document 9835 approves the use of CBLT in aviation English teaching for reasons of learning relevance of the subject matter, efficiency, cost-effectiveness and motivation. The ICAO document 9835:" Manual on the Implementation of ICAO Language Proficiency Requirements" proposes CBLT as a method to maximize and to 
economize the efficiency of an aviation English program (ICAO, 2010). With new instructions, Iran Airports and Air Navigation Company are running own aviation English training and testing programs for Iranian ATCOs according to ICAO Language Proficiency Requirements. The current aviation English courses held by the Iranian general directorate of ATM are very similar to the CBLT approach method.

\section{Aviation English}

Aviation English (AE) is a distinct register of English, not a dialogic style: abbreviated, a codified, full of special terms using Numbers Coupled with descriptors to transfer important information in summary form (International Civil Aviation Organization, 2004; Mauro, 2018).ATCOs' Uses Radiotelephony (RTF) to communicate with pilots and other relevant ATCOs. At first, it is significant to figure out ICAO's separation of phraseology and "plain language". Phraseology is a strongly proscribed collection of vocabulary that is limited by interactional rules, finite grammar, and some specifically adapted phonology (Brown, 2015; Byrne, 2013; Kline, 2015;Ikeda, 2013, Ikeda, 2016; Moder, 2013; Williams, 2016). Phraseology is primarily used for routine interactions. "Plain language" is used in those situations where phraseology is not sufficient (Barshi \& Farris, 2016; Emery, 2014; Kim \& Elder, 2009; Mauro, 2018; Raykov \& Marcoulides, 2012; Authority, C. A., 2010). Aviation English (AE) is one of the factors that have a great impact on the safety of flights and life of travelers (Zolfagharian, 2017).

\section{Aviation knowledge mastery}

As stated in ICAO Document, the Annex 11 (International Civil Aviation Organization, 2001, pp. 2-2) that the objectives of air traffic services can be defined as follows; (a) prevent collisions between aircraft; (b) prevent collisions between aircraft on the maneuvering area and obstructions on that area; (c) expedite and maintain an orderly flow of air traffic; (d) provide advice and information useful for the safe and efficient conduct of flights; and (e) notify appropriate organizations regarding aircraft in need of search and rescue aid, and assist such organizations as required.

Generally, aviation knowledge is the thing that an air traffic controller has understood because this one is learned when he or she was in scholar education. Controllers got some materials relating to the daily job they would face in the ground. There are too many subjects in term of improving their skill to handle and manage air traffic. In this context, controllers will get some knowledge whether theory or practice and even practical experience. As seen in the syllabus that it really concerns on the practical knowledge rather than theory one as stated on the syllabus (International Civil Aviation Organization (ICAO), 2009; International Civil Aviation Organization (ICAO); 2011, International Civil Aviation Organization (ICAO), 2013; Organization, I. C., 2017).

Meanwhile certification is the most important thing as well in which controllers has to get before joining other controllers doing their job. Controllers will be examined by certain checker controllers to reach passing grade as determined in the regulation. After passing the examination new controllers will get signature in their license from checker controllers that they are deserved to be controllers in certain jurisdiction.

The result of the test is usually based on the Standard Operating Procedure (SOP) in Air Traffic Services of controller. This SOP declares that; "Each license holder can have 
more than 1 (one) rating, a maximum of 3 (three) ratings; 1.14.9. Controller who carry out tasks in the work unit JATSC required to have a valid rating based qualifications after passed Proficiency Check (briefing, oral exam / oral, written exams and practice exams) (2018).

\section{Iranian studies aviation English}

Zolfagharian (2017) conducted a study to investigate needs analysis of aviation English for Iranian ATCOs. Participants of the study were 46 ATCOs, 7 content teachers, and 3 aviation English instructors. Most of the participants believe that aviation English instructors were good, rather good or very good, but about satisfaction, most respondents were not happy with most aspects of the class.

Barkhordari (2017) explored the needs analysis of Iran Air Airport Services Personnel in aviation English. Participants of the study were 130 employees working at Isfahan International Airport. They found that a revision of current professional training programs is necessary to provide curricula for appropriate ESP courses.

\section{International studies in aviation English}

In an investigation in (2018) Santos, Pacheco, Reyes, and Vargas examined methodologies applied in Aviation English Course. Participants were 15 pilots at a Military School in Salinas. The results of this study showed that some of the aspects of the methodology of the aircraft being taught at the school should be improved since all Participants were not familiar with the ICAO language skills guidelines.

Moskalenko and Didenko (2018) explored the relationship between computer tools and training pilots' listening skills in aviation English. Sample of this research were 76 fourth-year students, who perform practical flights. The results of empirical studies show that there is a positive change in the distribution of students' listening proficiencies in the phraseology of radio communication in English with the presentation of the computer tool: the number of students with high and intermediate listening skills has increased while listening skills have dropped to a low level.

In 2015, Kim and Elder investigated the construct of aviation English with feedback from test-takers in Korea. This research was conducted by examining the views of Korean airline pilots and ATCOs through 400 questionnaires and 22 sources of interviews. The results of this research show that there is a discrepancy between the structure of politics and reality through which the goals and objectives of the policy are realized. Also, strong refusal of the ICAO's espoused construct and the associated Korean English test from language users in the target domain.

\section{Performance}

An Air Traffic Controller as a part of job which provides services for pilot flying in defined airspace in order to achieve safely, efficient and effective is not well known for many people. Working in an area inside the airport, an Air Traffic Controller is difficult to recognize by other public community because an airport has some restriction for people to enter. (FAA Academy Airports and International Training Division, 2010), However, it is no longer exist, nowadays public society has been getting some 
knowledge about Air Traffic Controllers itself particularly when an accident occurs involving Air Traffic Controller investigation.

To carry out their job, controllers truly have mastered the aviation knowledge material provided in the exam every 6 month which is called as a performance check. Kind of questions in it has close relationship with controllers' understanding in daily work. It is essential one that controllers have fully comprehended the material moreover it has been learned several years ago when they studied in their school.

Another important thing based on the requirement, the rule stated on International Civil Aviation Regulation (ICAO) by International regulation that controllers have to achieve the level 4. Controllers might be tested with ICAO English Language Proficiency (IELP) routinely for every 3 or 6 year. This one is an essential part which controllers may work in controller working position if their English proficiency below level 4.

In providing services to pilot, controllers have to communicate with using English as media. In this context, controllers may not make mistake in order to give good services and avoid accident happened. Therefore, their English competence must be the need of the international standard required, however some controllers have weaknesses in listening skill particularly when pilot from foreigners speak out and discuss with them. Specific information that a pilot said sometimes was rather difficult to come up with by controllers consequently controllers were unable to respond pilot correctly. These weaknesses of controllers' listening might be indicated by the result of IELP. Some of them got low score on IELP test. Both aviation knowledge and listening comprehension were considered to influence IELP test score of controllers. Therefore, it might be important to know the correlation between aviation knowledge, listening comprehension and IELP. The result of this research would be valuable thing for controllers specifically in order to take account on those matters.

Performance can mean many things and has many definitions. Some people have this definition:" not so much about past achievements, as generally accepted, but about the future, about the capability of the unit evaluated" (Lebas, 1995, p.23). And elsewhere, researchers have two useful dimensions for meaning: "effectiveness of delivering desired outputs and efficiency of using as few inputs as possible to obtain the outputs" (Mäkilä, 2014, p.6).

To carry out their job,

\section{Iranian studies in performance}

Mohebbi and Masjedlou (2017) surveyed the challenges and reservations of planning content-based instruction in the Iranian EFL Setting. This research was conducted for 35 participant's performance on vocabulary, grammar, and subject matter related to the sciences in CBLT. To these goals, they used a pre-test, post-tests, matters for treatment, content knowledge of the learners, lexical and proficiency competence. Based on the results of this study, they concluded that According to statistical records, teaching science to General-English non-proficient learners Lead to high content performance, but a low vocabulary and grammar development. This research has been researched on the subject of CBLT challenges for Iranian EFL. But our research on CBLT assessment was another vocabulary skill for Iranian ATCOs'. 
Hashemyolia and Ayub (2014) investigated the effects of utilizing English language courseware on secondary school students' performance in Iran. Participants were $62 \mathrm{fe}$ male students. They concluded that English language courseware was an effective tool for teaching and learning the English language at the third-grade secondary school in Iran. This research has been researching a simple case and subject. But research in relation to a specialized subject and a professional and functional subject is necessary.

In 2013, Chermahini, Ghanbari, and Talab worked on Learning styles and academic performance of students in English as a Second-Language class in Iran. Participants were 488 high school students (248 male and 240 female). They indicated significant relationships between the different learning styles and the performance in an English test, and the learning styles can be considered as a good predictor of any second language academic performance.

\section{International studies in performance}

Cawagdan and Rivera (2018) explored the learners' use of language learning strategies (LLS) and determine its relationship with the English proficiency test performance of college students $(N=8)$. They used a descriptive correlational study. Results showed that memory, metacognitive, cognitive, compensation, organizing, and evaluation and affective learning strategies do not significantly affect students' English proficiency test performance; whereas social learning strategies is a strong predictor of students' English proficiency test performance. Moreover, they didn't work on the aviation field.

In 2018, Santikarn and Wichadee searched to assess how a modified "flipped classroom" had an impact on students' learning performance and perceptions. Participants of the study were 40 students from one section enrolled in an advanced English course. Their research findings showed that after the students were taught in the flipped classroom, their English scores were satisfactory. The results showed that most students were satisfied with lecture videos and Edmodo, the learning platform.

Tsai and Shang (2010) examine students' attitudes and the effect of CBLT on reading performance. Participants were 101 sophomores majoring in English at I-Shou University in southern Taiwan. Results indicated that the utilization of CBLT in the literature class could enhance students' reading comprehension as well as critical thinking ability.

\section{Method}

\section{Design}

This study reports on an exploratory study. In the current study, the attitude had been used as an independent variable and the dependent variable was proficiency. Also, the performance had been used as a Mediator variable. The explanatory variables of our study were: 1) The current aviation English courses (CBLT courses) held by the Iranian general directorate of ATM, and 2) The work experience of the participants in the research was an independent variable. In the following, the researchers analyzed the relationship between the variables by statistical test and software.

\section{Participants}

The participants involved in this study were Iranian ATCOs.. Researchers used cluster random sampling from 1000 Iranian ATCOs for our research. The Number of 
participants was 278 which were calculated by the Cochran formula (5\% error). They were suitable for this study because they have all passed general English language courses; aviation English courses, as well as on the job training (OJT) courses.

\section{Instrument}

The questionnaire was composed of two sections: A) Ten multiple-choice questions for assessment of the current Aviation English courses (CBLT courses) held by the Iranian general directorate of ATM (Q1 to Q10). B) Ten multiple-choice questions for assessment Iranian ATCOs' attitudes toward using CBLT approach in the current Aviation courses held by the Iranian general directorate of ATM to practice English vocabulary skill in emergency or abnormal situations (Q11 to Q20).

The closed-ended questions in the questionnaire were designed to explore: CBLT (Q1 to 12, and Q20), attitude (Q1, Q2, Q4, Q5, Q11 to15, Q18 to20), proficiency (Q6 to10), vocabulary(Q1 to3, Q5, Q11 to19), Emergency situations or abnormal situations(Q1 to4, Q10, Q12, Q14, Q18, Q19), performance(Q3, Q16).

\section{Procedure}

Pilot study

In this way, 35 Iranian ATCOs' who were participants in the main study were selected as participants in the pilot study. The scholars piloted the questionnaires and as a result, the learners' participants that they had no problems in knowing and answering the questionnaire. In addition, the researchers had estimated the time it takes to answer each questionnaire.

\section{Main study}

The Number of participants was 278. All participants in the program answered the questionnaire, and participants had enough time to answer the questionnaire. We also ensured the participants that their participation in this research was voluntary and the data collected by means of the questionnaires will be kept confidential. The quantitative data were collected from questionnaires. Afterward, the normality of the data was examined via the one-sample Kolmogorov-Smirnov (K-S) test. Finally, data analyzed by SPSS software version 24.0 and AMOS software version 23.0. Chapter four shows the results of the study.

\section{Backward and forward translation}

The questionnaire was translated into Farsi in order to ensure that the Iranian ATCOs answers to the questionnaire correctly. At first, the English questionnaire versions were given to two expert translators to translate them into Farsi language, and then, two other expert translators were asked to translate the Farsi versions of the questionnaires into English language and these versions were compared by the original English questionnaires by two other experts in English language and finally, Farsi versions of the questionnaires which were the most appropriate translated version was selected as the questionnaire of the current research. 


\section{Validation and reliability of the instruments}

Accordingly, the instrument used in this research, validated by some asking some experts in English language teaching and university professors to comment on the accuracy of the questionnaire used in this research. The questionnaires were validated by 10 experts to determine which ones were essentials, and their content validity was evaluated using Lawsh CVR (Content Validity Ratio) and CVI (Content Validity Index). (Gürsoy \& Eken, 2018; Lawshe, 1975; Waltz \& Bausell, 1981). After conducting the piloting of the questionnaires based on CVR and CVI, the researchers kept 20 questions for measuring the research needs.

\section{Data analysis}

The quantitative data collected by the questionnaires. In this research, we used two statistical analysis software for windows. One of the software was the statistical packages for social sciences (SPSS 24.0), and the other was the analysis of moment structures (AMOS 23.0). The quantitative data entered into SPSS 24.0 and AMOS 23.0. Then, they analyzed by the researchers. In this study, descriptive and inferential statistics were presented. For each statistical test, a number of conditions must be met before analyzing. These conditions must be checked because the accuracy of the test's interpretation depends on this. The following statistical tests have been used to analyze the study data: The Kolmogorov-Smirnov test (Normality data test), the Structural Equation Model, the Path Analysis Model, and Confirmatory Factor Analysis.

\section{Results}

Work experience, and number of aviation English courses spent by participants

In Fig. 1, the frequency distribution of respondents was shown based on their work experience, and based on the latest aviation Courses that participants have been spent.

\section{Descriptive analysis of main variables of research}

In this section, researchers described the descriptive analysis of the main variables of the research. In the following tables, the descriptive indexes and the frequency of

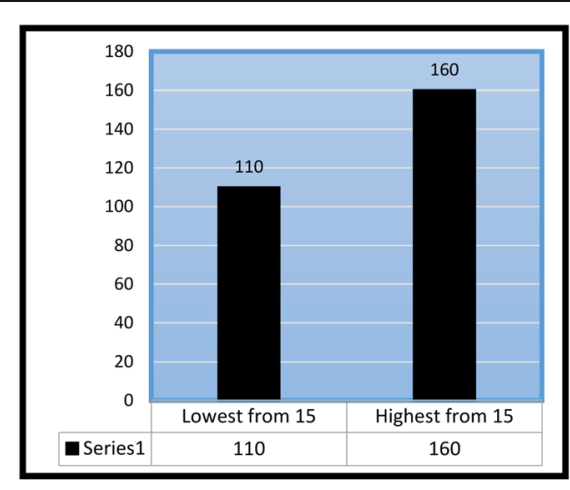

Work experience

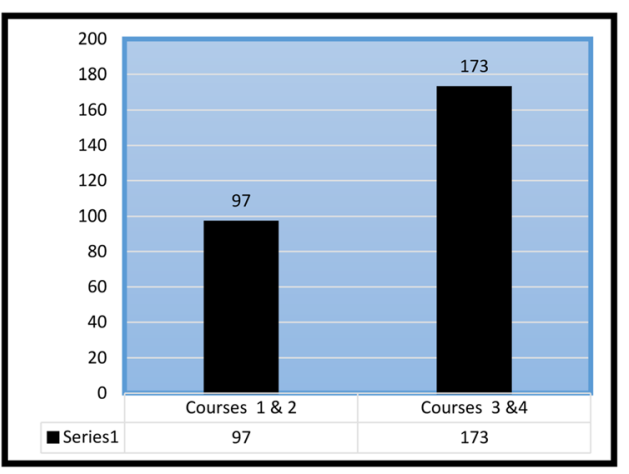

Latest aviation Courses that participants have spent

Fig. 1 Bar graphs of respondents based on their work experience, and their latest aviation Courses that participants have spent 
Table 1 Determining the level of the scores of variables

\begin{tabular}{ll}
\hline Total Scores & Level \\
\hline 1 to 2.339 & low \\
2.34 to 3.669 & medium \\
3.67 to 5 & up \\
\hline
\end{tabular}

answers to the questions related to each of the variables were shown. To determine the level of the questionnaire, the 5th spectrum was divided into three groups: low, medium, and up (Table 1). Firstly, due to the Likert-scale (1 to 5) in academic resilience questionnaire (strongly disagree to strongly agree), college academic self-efficacy scale (CASES) (very little to quite a lot), the total score for these three questionnaires was four $(4=5-1)$, so the distance between each floor was $1.33=4 \div 3$. Therefore, the level of the questionnaire was determined according to the following table:

According to Tables 2 and 3, the average of all proficiency variable questions was 3.64, the average of all attitude variable questions was 4.16, and the average of all performance variable questions was 4.144 , there was higher than the theoretical average (3). This result can also be concluded for the sub-components of the total proficiency variable. This mentions that the respondents selected options 4 and 5 in response to the questionnaire. On the other hand, given that the values of Skewness and Kurtosis were between ( -1 and 1$)$, so the data were almost nearnormal distribution. The results of leveling the items related to different variables of research in three levels of low, moderate, and up showed that: Therefore, respondents were at a medium or up level of performance, proficiency, and attitude (Table 3).

Table 2 shows the central indices and scatter of the variables Performance, Proficiency and Attitude. According to the table, the variables Skewness and Kurtosis are between $(-2,2)$ and show that the data distribution is normal. In the following, we divided the values obtained from the variables into three parts: upper, middle and lower limits, and reported the number and percentage of data in these limits. The upper limit indicates the number of supporters, the middle limit indicates the number of dissenters, and the lower limit indicates the number of opponents in each variable.

Table 2 Frequency distribution and descriptive indexes of responses related to the variable of performance, proficiency, and attitude

\begin{tabular}{|c|c|c|c|c|c|c|c|}
\hline & Mean & Std. Deviation & Skewness & Kurtosis & & Frequency & Percent \\
\hline \multirow[t]{3}{*}{ Performance } & 4.144 & .449 & -.015 & .320 & Low & 0 & 0.0 \\
\hline & & & & & medium & 41 & 15.2 \\
\hline & & & & & up & 229 & 84.8 \\
\hline \multirow[t]{3}{*}{ Proficiency } & 3.641 & .533 & -.049 & .236 & Low & 4 & 1.5 \\
\hline & & & & & medium & 143 & 53.0 \\
\hline & & & & & up & 123 & 45.6 \\
\hline \multirow[t]{3}{*}{ Attitude } & 4.157 & .4822 & .034 & .108 & Low & 0 & .00 \\
\hline & & & & & medium & 40 & 14.8 \\
\hline & & & & & up & 230 & 85.2 \\
\hline
\end{tabular}


Table 3 Frequency distribution and descriptive indexes of responses in proficiency variables and related items

\begin{tabular}{|c|c|c|c|c|c|c|c|}
\hline & Mean & Std. Deviation & Skewness & Kurtosis & & Frequency & Percent \\
\hline \multirow[t]{3}{*}{ reading } & 3.674 & .770 & -.056 & -.406 & Low & 14 & 5.2 \\
\hline & & & & & medium & 89 & 33.0 \\
\hline & & & & & up & 167 & 61.9 \\
\hline \multirow[t]{3}{*}{ Listening } & 3.744 & .764 & -.233 & -.238 & Low & 5 & 1.9 \\
\hline & & & & & medium & 71 & 26.3 \\
\hline & & & & & up & 194 & 71.9 \\
\hline \multirow[t]{3}{*}{ writing } & 3.667 & .780 & -.283 & -.238 & Low & 8 & 3.0 \\
\hline & & & & & medium & 87 & 32.2 \\
\hline & & & & & up & 175 & 64.8 \\
\hline \multirow[t]{3}{*}{ Presentations } & 3.759 & .709 & -.120 & -.211 & Low & 1 & .4 \\
\hline & & & & & medium & 81 & 30.0 \\
\hline & & & & & up & 188 & 69.6 \\
\hline \multirow[t]{3}{*}{ Discuss } & 3.978 & .297 & -.348 & .529 & Low & 4 & 1.5 \\
\hline & & & & & medium & 61 & 22.6 \\
\hline & & & & & up & 205 & 75.9 \\
\hline \multirow[t]{3}{*}{ Proficiency } & 3.641 & .533 & -.049 & .236 & Low & 4 & 1.5 \\
\hline & & & & & medium & 143 & 53.0 \\
\hline & & & & & up & 123 & 45.6 \\
\hline
\end{tabular}

Table 3 shows the central indices and scatter of the variables reading, Listening, writing, Presentations, Discuss, and Proficiency. According to the table, the variables Skewness and Kurtosis are between $(-2,2)$ and show that the distribution of data is normal. In the following, we divided the values obtained from the variables into three parts: upper, middle and lower limits, and reported the number and percentage of data in these limits. The upper limit indicates the number of supporters, the middle limit indicates the number of dissenters, and the lower limit indicates the number of opponents in each variable.

\section{Inferential statistics}

We used Kolmogorov-Smirnov test to check the normality of the variables. In all of the finding of research, the $p$-values were greater than 0.05 . Therefore; there was no significant difference between the distributions of samples with normal distribution (Table 4).

Table 4 The output of the Kolmogorov-Smirnov test to verify the normality of the performance, proficiency, and attitude variables

\begin{tabular}{lllll}
\hline & & Proficiency & Attitude & Performance \\
\hline $\mathrm{N}$ & & 270 & 270 & 270 \\
Normal Parameters $^{\mathrm{a}}$ & Mean & 3.641 & 3.979 & 4.1600 \\
& Std. Deviation & .533 & .2960 & .43126 \\
Most Extreme Differences & Absolute & .078 & .085 & .274 \\
& Positive & .078 & .083 & .274 \\
Kolmogorov-Smirnov Z & Negative & -.076 & -.083 & -.272 \\
Asymp. Sig. (2-tailed) & & 1.280 & 1.313 & 1.240 \\
\hline
\end{tabular}

${ }^{\mathrm{a}}$ Test distribution is Normal 
Path analysis was an extension of multiple regressions. It goes beyond regression, where more complex model analysis is possible. Path analysis was a subcategory of Structural Equation Modeling (SEM) (Kunstmann, 2003; Pennell, 2017; Streiner, 2005). One of the important aspects of path analysis and SEM is Confirmatory Factor Analysis (CFA). In the CFA, certain assumptions about the structure of Factor Loading and the correlations between the variables are tested (Brown, 2015; Byrne, 2013; Kline, 2015). The results of the evaluation of the final measurement model of the dependent variable of proficiency were presented in Fig. 2. Based on the various fit index, the model has suitable goodness of fit based on the relevant indicators (Table 5).

The results presented in Table 5, indicated the relative suitability of the indexes. According to the output of the Amos software, the calculated $X^{2}$ was equal to 6.987, which was less than the number 3 relative to its Degree of Freedom (DF). The low level of this index indicates a slight difference between the conceptual model and the observed data of the research. The RMSEA value was 0.053. The GFI, NFI, IFI, and CFI indices were $0.990,0.968,0.986$, and 986 respectively, indicating that they were suitable for Fitting.

The results presented in Table 6, indicated the relative suitability of the indexes. According to the output of the Amos software, the calculated $2 x$ was equal to 6.987, which was less than the number 3 relative to its Degree of Freedom (DF). The low level of this index indicates a slight difference between the conceptual model and the observed data of the research. The RMSEA value was 0.053. The GFI, NFI, IFI, and CFI indices were $0.990,0.968,0.986$, and 986 respectively, indicating that they were suitable for Fitting. The table below shows the Factor Loadings and the Level of Significance

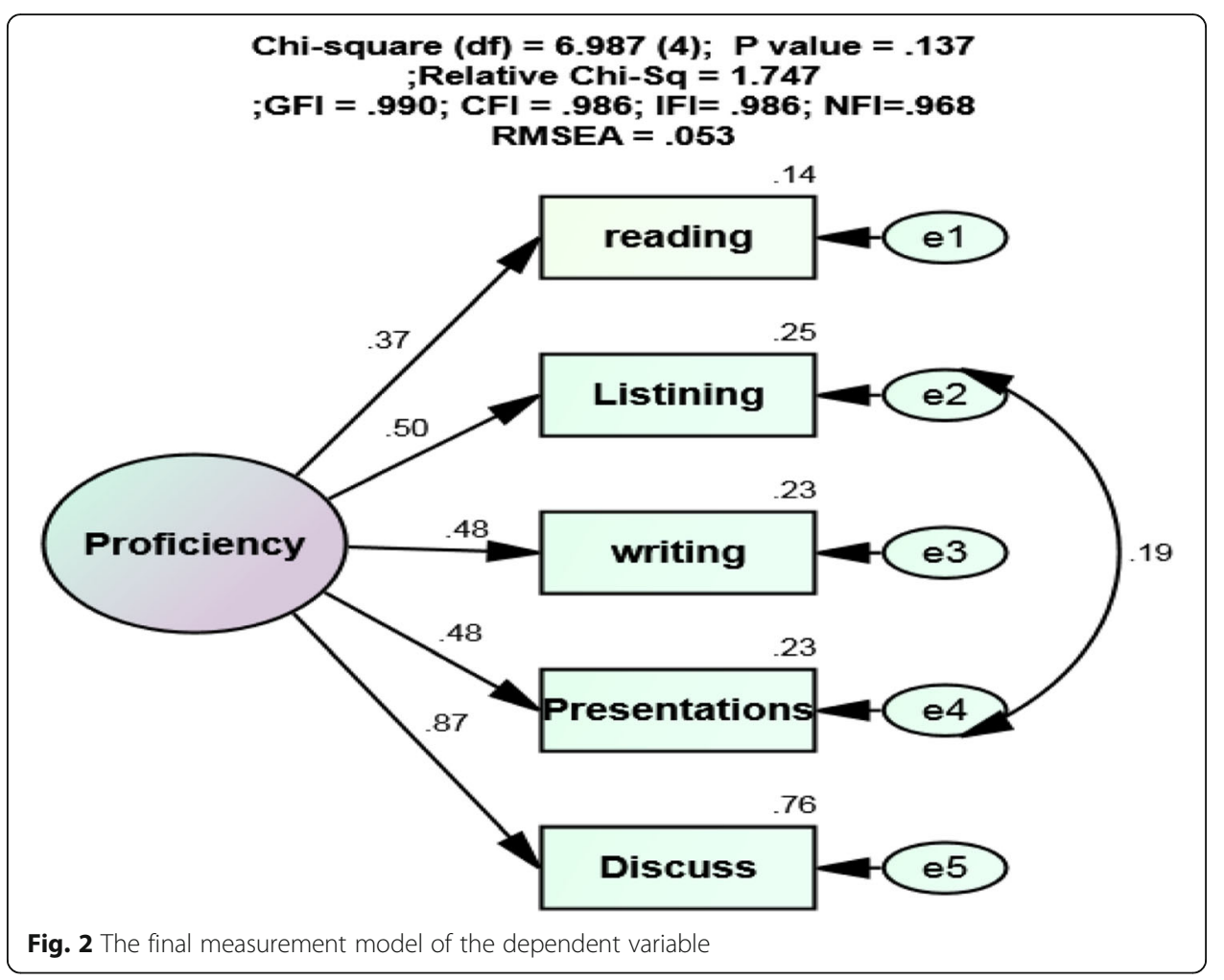


Table 5 Goodness of fit index (GFI) for the proficiency Model

\begin{tabular}{lll}
\hline Fitting Index & Desirable amount & Result \\
\hline $\mathrm{df}^{2} \mathrm{X}$ & $3.00>$ & 1.747 \\
GFI(goodness of fit index) & $0.90<$ & 0.990 \\
RMSE(Root Mean Squared error) & $0.08>$ & 0.053 \\
IFI )Incremental Fit Index ( & $0.90<$ & 0.986 \\
$\mathrm{NFI}($ Normed Fit Index) & $0.90<$ & 0.968 \\
CFI(Comparative Fit Index) & $0.90<$ & 0.986 \\
\hline
\end{tabular}

( $P$-value) for each of the variables. It should also be noted that for the better Fitting, The Covariance Model was released between two Listening and Discuss variables. The results of evaluating the Convergent Validity of the Proficiency variable as shown in Table 6 showed that: All items had a Factor Loading greater than 0.3. The ability to discuss with the coefficient of 0.871 has the most impact on the Proficiency variable, and the reading power with the coefficient of the path of 0.370 has the least impact on the Proficiency variable.

The main model of the study, shown in Fig. 3, showed the Estimating Factor Loading in Estimating Standard Mode. If the Factor Loading was between 0.2 to 0.6, it was desirable, and if Factor Loading was bigger than 0.6, it was very desirable (Bentler \& Weeks, 1980; Byrne, 2013; Loehlin, 2004; Raykov \& Marcoulides, 2012). In this study, we considered the accepted Factor Loading to be equal to 0.3. The results of the fitting indices showed that the fitting was suitable for the model and the fitting indices were within the accepted range. The results presented in Table 7, indicate the relative suitability of the indexes. According to the output of the Amos software, the calculated $2 \mathrm{X}$ was equal to 28.310 , which was less than the number 3 relative to its Degree of Freedom (DF = 12). The low level of this index indicated a slight difference between the conceptual model and the observed data of the research. The RMSEA value was 0.071. The GFI, NFI, IFI, and CFI indices were 0.971, 0.940, 0.901, and 0.938 respectively, indicating that they were suitable for Fitting. One of the main goals of constructing a structural model was: determine the strength, direction, and significance of the path coefficients assumed in the conceptual model of research in the form of research hypotheses. The results of the structural model in relation to the test of other hypotheses of this study showed that:

The results presented in Table 7, indicate the relative suitability of the indexes. According to the output of the Amos software, the calculated $2 \chi$ was equal to 28.310, which was less than the number 3 relative to its Degree of Freedom $(D F=12)$. The low level of this index indicated a slight difference between the conceptual model and the observed data of the research. The RMSEA value was 0.071 . The GFI, NFI, IFI, and CFI

Table 6 Standardized Regression Weights: (data - Default model)

\begin{tabular}{llllll}
\hline & & & Estimate & C.R. & P \\
\hline Reading & $\rightarrow$ & Proficiency & .370 & 5.635 & .00 \\
Listening & $\rightarrow$ & Proficiency & .504 & 4.772 & .00 \\
writing & $\rightarrow$ & Proficiency & .483 & 4.704 & .00 \\
Presentations & $\rightarrow$ & Proficiency & .482 & 4.680 & .00 \\
Discuss & $\rightarrow$ & Proficiency & .871 & 4.874 & .00 \\
\hline
\end{tabular}




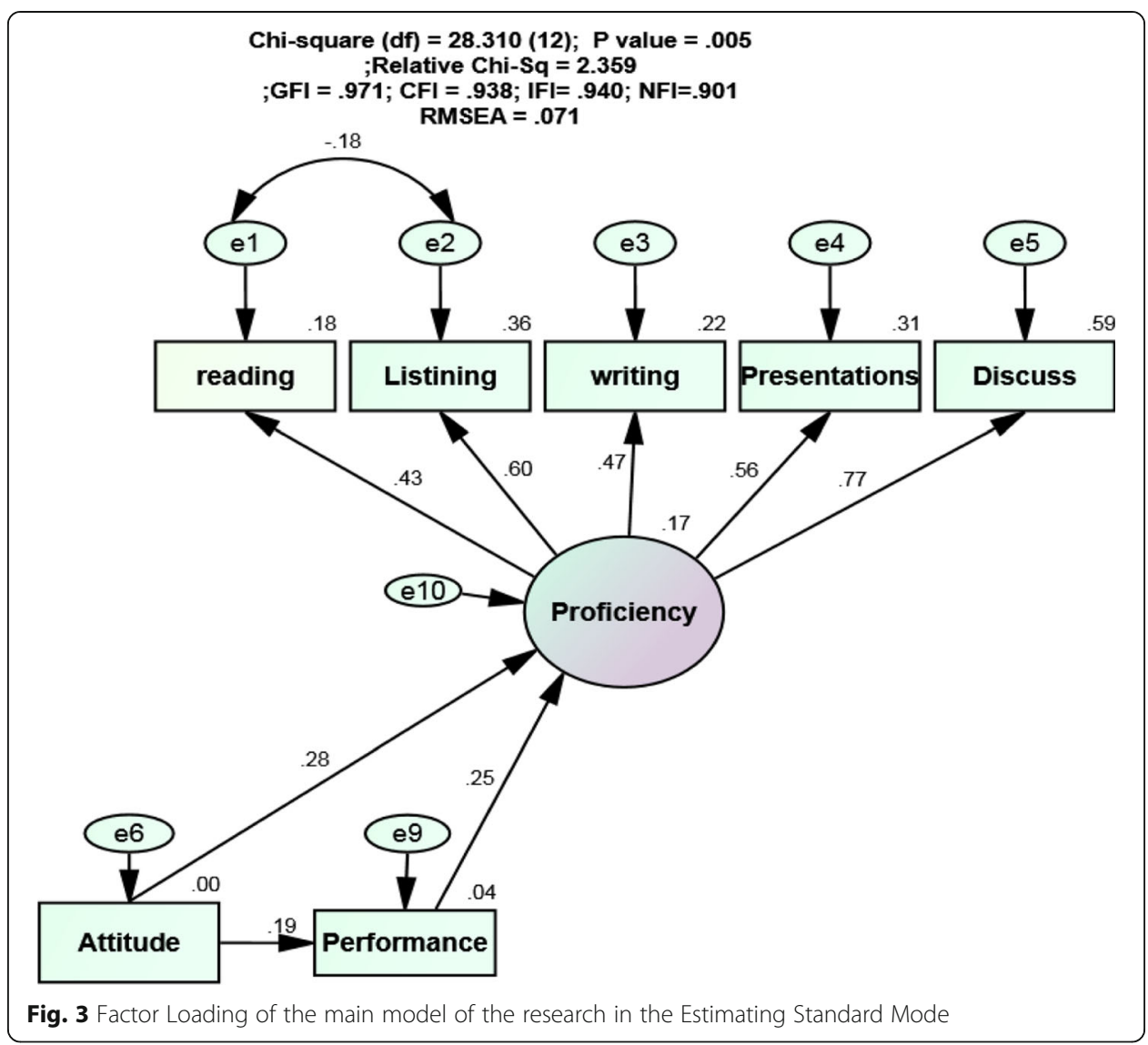

indices were $0.971,0.940,0.901$, and 0.938 respectively, indicating that they were suitable for Fitting.

\section{Performance and proficiency of individuals}

In this section, we investigated that the performance has a significant positive effect on the proficiency of individuals. According to the path analysis, Table 8, and Fig. 3 were showed that: Factor Loading between performance and proficiency of individuals was 0.254, the critical ratio (C.R) was 3.300, whose absolute value was greater than 1.96. Therefore, and we can conclude that with the probability of $95 \%$, the performance has a positive and significant effect on the proficiency of individuals. Finally, according to

Table 7 Goodness of fit index (GFI) for the main model

\begin{tabular}{lll}
\hline Fitting Index & Desirable amount & Result \\
\hline df $^{2} X$ & $3.00>$ & 2.359 \\
GFI(goodness of fit index) & $0.90<$ & 0.971 \\
RMSE(Root Mean Squared error) & $0.08>$ & 0.071 \\
IFI )Incremental Fit Index ( & $0.90<$ & 0.940 \\
NFI(Normed Fit Index) & $0.90<$ & 0.901 \\
CFI(Comparative Fit Index) & $0.90<$ & 0.938 \\
\hline
\end{tabular}


Table 8 Standardized Regression Weights: (data - Default model)

\begin{tabular}{|c|c|c|c|c|c|}
\hline & & & Estimate & C.R. & $\mathbf{P}$ \\
\hline Performance & $---<$ & Proficiency & .254 & 3.300 & .000 \\
\hline
\end{tabular}

the amount (Significance $=0.000 ; \beta=0.254$ ), it can be concluded that in order to increase the unit of performance, the proficiency of individuals increases by 0.25 units.

Performance, proficiency, and work experience of individuals In this segment, we checked that in the effect of performance on proficiency, work experience has a positive moderating role. In order to test the effect of independent variables on proficiency based on the moderation of respondents' work experience, a multi-group analysis technique was used. For this purpose, AMOS statistical software was used. Accordingly, respondents were first divided into two groups of work experience (less than 15 and more than 15). According to the path analysis, Table 9, Figs. 4, and 5 were showed that: Factor Loading of moderating effect of the variable of work experience, in relation to the effect of performance towards proficiency in people with low work experience was 0.268 , and in people with high work experience was 0.282 . Also, the value of the critical ratio (C.R) in the groups with low work experience and high work experience were respectively 2.324 and 2.350; whose absolute value was greater than 1.96 .

Therefore, we can conclude that with the probability of $95 \%$, in the effect of performance on proficiency, work experience had a positive moderating role.

Performance, proficiency of individuals, and aviation English courses In this section, we investigated that in the effect of performance on proficiency, passing aviation English courses (CBLT courses) has a positive moderating role. In order to test the effect of independent variables on proficiency, based on the moderation of passing current aviation English, a multi-group analysis technique was used. For this purpose, AMOS statistical software was used. Accordingly, respondents were first divided into two groups of passing current aviation English (passing course1 \&2 and passing course3 \&4). According to the path analysis, Table 10, Figs. 6, and 7 were showed that: Factor Loading of moderating effect of the variable of passing aviation English courses, in relation to the effect of performance towards proficiency in people that they passed courses1, 2 was 0.054, and in people that they passed courses2, 3 was 0. 392. Also, The value of the critical ratio (C.R) was respectively 1.192and 2.234, whose absolute value was greater than 1.96 . Therefore, we can conclude that with the probability of $95 \%$, in the effect of performance on proficiency, passing aviation English courses had a positive moderating role.

Table 9 Standardized Regression Weights: (data - Default model) for work experience of participants

\begin{tabular}{lllllll}
\hline & & & & Estimate & C.R. & P \\
\hline Lower 15 & Performance & $---<$ & Proficiency & .268 & 2.324 & .000 \\
Upper 15 & Performance & $---<$ & Proficiency & .282 & 2.350 & .000 \\
\hline
\end{tabular}



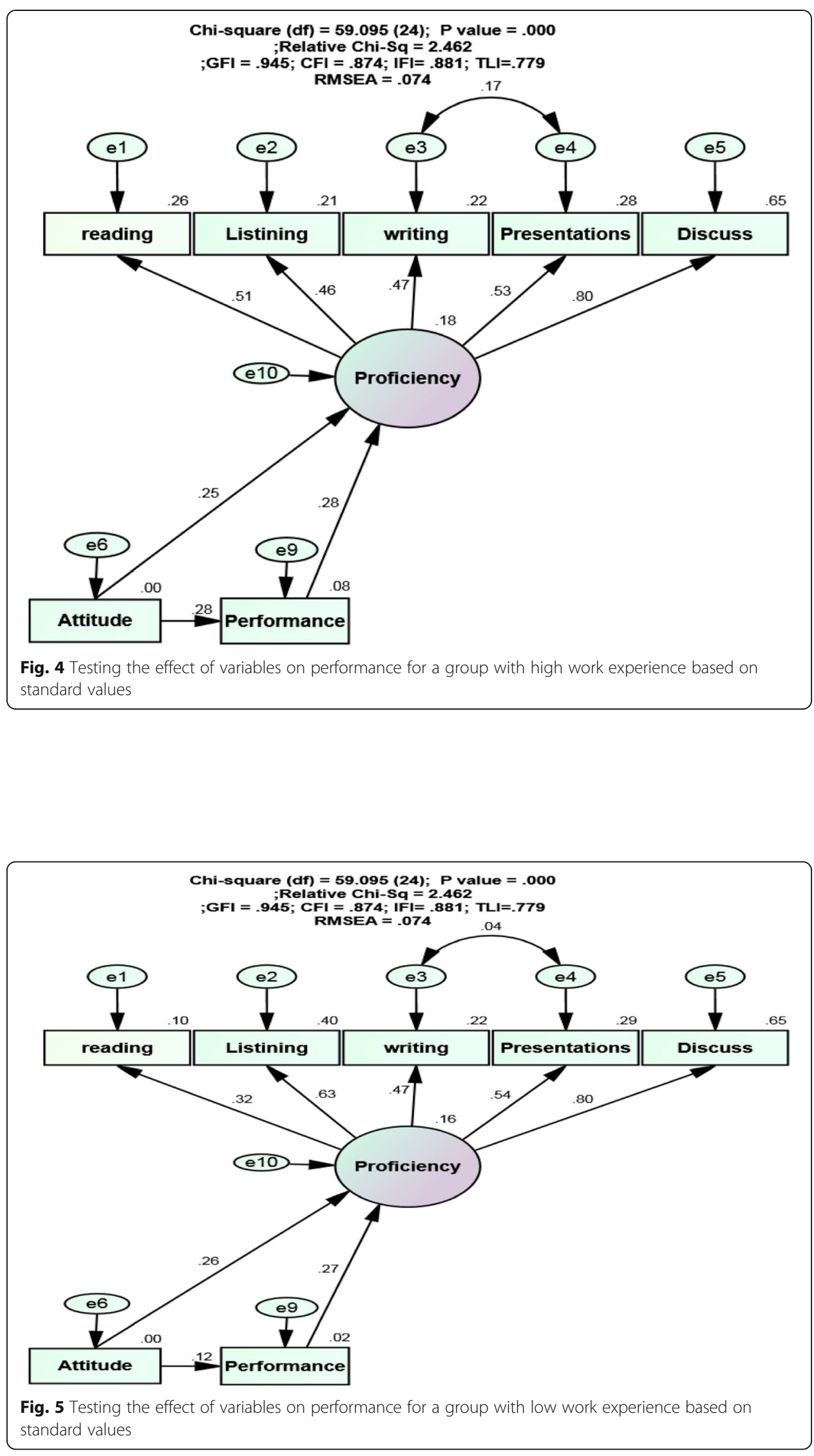
Table 10 Standardized Regression Weights: (data - Default model) for participants that they passed current Aviation courses (CBLT courses) held by the Iranian general directorate of ATM

\begin{tabular}{lllllll}
\hline $\mathbf{I}$ & & & & Estimate & C.R. & P \\
\hline passing course1 \&2 & Performance & $---<$ & Proficiency & .054 & 1.192 & .000 \\
passing course 3\&4 & Performance & $---<$ & Proficiency & .392 & 2.234 & .000 \\
\hline
\end{tabular}

\section{Proficiency and attitudes of individuals}

Proficiency, attitudes and work experience of individuals In this segment, we checked that in the effect of attitude on proficiency, work experience had a positive moderating role. According to the path analysis, Table 11, Figs. 4, and 5 were showed that: Factor Loading of moderating effect of the variable of work experience, in relation to the effect of attitude towards proficiency in people with low work experience was 0.262 , and in people with high work experience was 0.254 . Also, The value of the critical ratio (C.R) in the groups with low work experience and high work experience was respectively 3.214and 2.162, whose absolute value was greater than 1.96 . Therefore, we can conclude that with the probability of $95 \%$, in the effect of attitude on proficiency, work experience did not have a positive moderating role and it has a negative moderating role.

Proficiency, attitudes of individuals, and aviation English courses In this section, we investigated that in the effect of attitude on proficiency, passing aviation English courses (CBLT courses) has a positive moderating role. According to the path analysis, Table 12, Figs. 6, and 7 were showed that: Factor Loading of moderating effect of the variable of passing current aviation English courses, in relation to the effect of attitude towards proficiency in people that they passed courses 1,2 was 0.379 , and in people that they passed

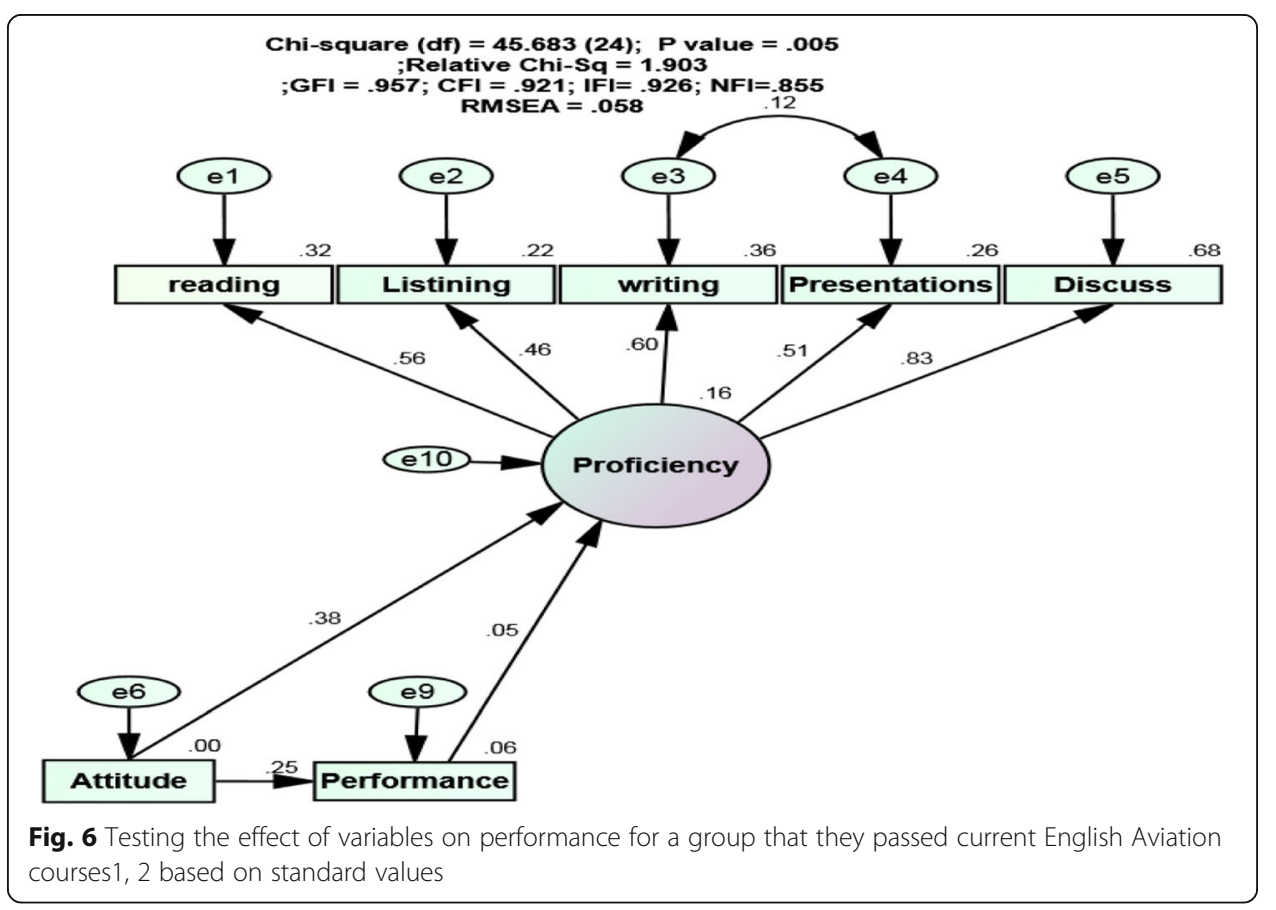




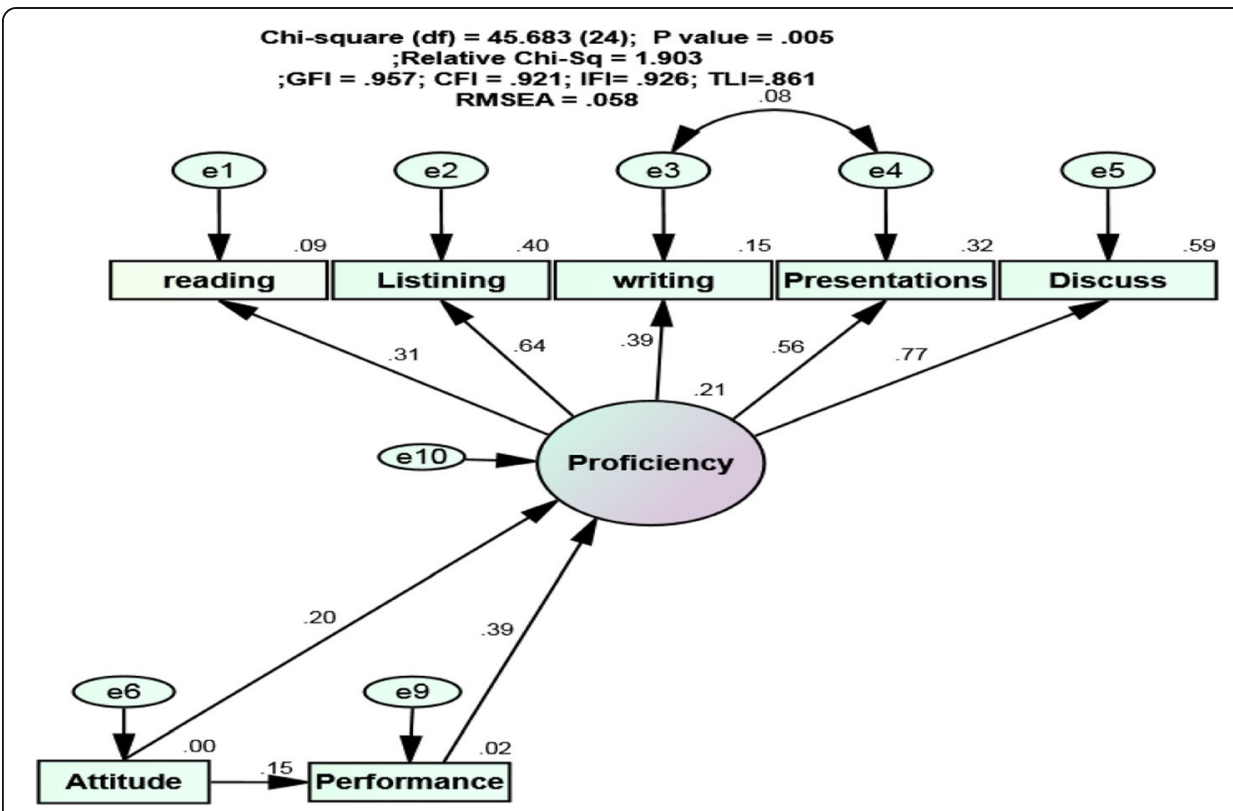

Fig. 7 Testing the effect of variables on performance for a group that they passed current Aviation English courses 3,4 based on standard values

courses 2,3 is 0.201 . Also, the value of the critical ratio (C.R) was respectively 2.947 and 3.241, whose absolute value was greater than 1.96.Therefore, we can conclude that with the probability of $95 \%$, in the effect of attitude on proficiency, passing aviation were courses did not have a positive moderating role and it has negative moderating role.

\section{Discussion}

In this study, the relationship between performance and proficiency of Iranian ATCOs was investigated. Also, the role of their Attitude, work experience, and Aviation English courses was explored. Interestingly, the findings of this research were in line with the findings of the previous studies in the current field: Barkhordari (2017), Chermahini, Ghanbari, and Talab (2013), Hashemyolia and Ayub (2014), Kim and Elder (2015), Santikarn and Wichadee (2018), Santos, Pacheco, Reyes, and Vargas (2018), Tsai and Shang (2010), Zolfagharian, 2017.

On the whole, the results of this study focused on the significance of the performance of Iranian ATCOs on their proficiency. According to the questionnaire results, and results of the above hypothesis, firstly, the performance had a significant positive effect on the proficiency of individuals. Secondly, In the effect of performance on proficiency, work experience has a positive moderating role. Finally, in the effect of performance on proficiency, passing aviation English courses has a positive moderating role. More importantly, the findings of the current research, in particular, can be a good suggestion

Table 11 Standardized Regression Weights:(Data-Default model) for work experience of participants

\begin{tabular}{lllllll}
\hline & & & & Estimate & C.R. & P \\
\hline Lower 15 & Attitude & $---<$ & proficiency & .262 & 3.214 & .000 \\
Upper 15 & Attitude & $---<$ & proficiency & .254 & 2.162 & .000 \\
\hline
\end{tabular}


Table 12 Standardized Regression Weights: (data - Default model) for participants that they passed current Aviation courses (CBLT courses) held by the Iranian general directorate of ATM

\begin{tabular}{lllllll}
\hline & & & & Estimate & C.R. & P \\
\hline passing course1 \&2 & Attitude & $---<$ & Proficiency & .379 & 2.947 & .000 \\
passing course 3 \& 4 & Attitude & $---<$ & Proficiency & .201 & 3.241 & .000 \\
\hline
\end{tabular}

for the English teachers and Iranian general directorate of ATM to have a successful teaching and also motivated learners.

Therefore, in order to discuss the basis for this difference, the performance had a positive impact on proficiency. as well as, work experience had a good mediator between performance and proficiency, while, passing aviation English courses had a good mediator between performance and proficiency.

According to the findings of the previous research by Tsai and Shang (2010) that students' attitudes and the effect of CBLT on reading performance. The results of the research indicate that the utilization of CBLT in the literature class could enhance students' reading comprehension as well as critical thinking ability. Santikarn and Wichadee (2018) points out that after the students were taught in the flipped classroom, their English scores were satisfactory. Chermahini et al. (2013) counsels that significant relationships between the different learning styles and the performance in an English test.

In general, the results of this study pointed to the important role of work experience and CBLT courses in the effect of attitude on proficiency. According to the questionnaire results, and results of the above null hypothesis, firstly, in the effect of attitude on proficiency, work experience had not a positive moderating role and it had a negative moderating role. Secondly, in the effect of attitude on proficiency, passing aviation English courses had not a positive moderating role and it had a negative moderating role. More importantly, the findings of the current research, in particular, can have been a good suggestion for the English teachers and Iranian general directorate of ATM to have a successful teaching and also motivated learners. Therefore, In order to discuss the basis for this difference, work experience and CBLT courses in the effect of attitude on proficiency had not a good mediator. There were limits to this study that was beyond the control of the scholars. Such as 1) the study focused only on several ATS units of the total operational ATS units of Iran.2) the sample was a cluster random sampling drawn from Iranian ATCOs'. Generalizing results to the entire population of Iranian ATCOs was difficult due to the differences in demographics of training and attitudes of ATCOs of the whole country.

The findings of the present study can be discussed considering the fact that aviation English classrooms are complicated places. Classrooms are places where people, normally one teacher and a number of learners, come together for a pedagogical purpose. However, in addition to their physical (or virtual) location and pedagogic function, classrooms are also social environments, that is, language lessons can be understood as social events based upon social relationships and social interaction. As noted earlier, aviation English classes were complicated classes. In discussing the findings, it can be stated that as Hall (2011) believes, diversity and complexity are basic elements of language teaching and learning, and of language classrooms. Each classroom is distinctive; and this human and contextual complexity makes classroom language teaching chaotic. 
What happens in a classroom is certainly much more than the logical application of theories and principle; it is localized, situation-specific, and, therefore, diverse.

This study shed more light on the assessment of proficiency and performance of Iranian Air Traffic Controllers, with more attention on attitude, work experience and specific aviation English courses (CBLT courses) held by the Iranian general directorate of ATM. Further studies were needed to investigate the effect of CBLT on aviation English learning of personnel of aviation industry in Iran. Also, further research could expand on this study by including a number of additional factors. There were many aspects of assessment in CBLT courses which had not been addressed. Five subjects were included in this study: ATCOs, CBLT courses, attitude, performance, and proficiency. The results of the present study would benefit for more in-depth research within the above subjects, and as well as an inclusion of other subjects.

In other studies, involving aviation staff, other data gathering methods could be used, such as: interview, observation, exam, etc. And also, other data analysis ways could be used. The present study has been limited to questionnaire. Future research could include classroom studies to better understand context and the alignment between course content, classroom practice and assessment procedures. In addition, the study was limited to the Iranian ATCOs' view, but changing focus on teachers and testers was also valuable. Eventually, more specific studies of the factors affecting ATCOs' attitude, performance, and proficiency would also benefit.

Finally, it might be of interest to compare the results of the present questionnaire to a larger sample. The results from this study confirmed the idea that it was important to carry out extensive research to better understand the nature of the language used in ATCOs and pilot's communications and ICAO LPRs.

\section{Conclusion}

In this section, the overall findings of the current study presented. According to the research hypotheses of this study, five main conclusions were presented:

1. Based on the researchers' findings, they concluded that Iranian ATCOs' performance had a positive and significant effect on their proficiency.

2. The findings of this study show that in the effect of Iranian ATCOs' performance on their proficiency, work experience had a positive moderating role.

3. This research points out that in the effect of Iranian ATCOs' performance on their proficiency; passing aviation English courses had a positive moderating role.

4. The Iranian ATCOs' showed that in the effect of their attitude on their proficiency, work experience did not have a positive moderating role and it had a negative moderating role.

5. The Iranian ATCOs' indicated that in the effect of their attitude on their proficiency, passing aviation English courses did not have a positive moderating role and it had a negative moderating role.

A number of questions related to the CBLT, aviation English, and vocabulary proficiency had been raised in this study and warrant further investigation. Due to the limitations of this study, further studies have been proposed. This study 
shed more light on the assessment of CBLT on Iranian ATCOs' vocabulary proficiency in emergency or abnormal situations, with more attention on attitude, performance, proficiency. More studies were needed to investigate the effect of CBLT on aviation English learning of personnel of aviation industry in Iran. Also, further research could expand on this study by including a number of additional factors. The focus in this study has been on Iranian ATCOs' and their assessment practices in current aviation English courses (CBLT courses) held by the Iranian general directorate of ATM. There were many aspects of assessment in CBLT courses which had not been addressed. Seven subjects were included in this study: ATCOs, CBLT courses, vocabulary proficiency, emergency or abnormal situations, attitude, performance, and proficiency. The results of the present study would benefit for more in-depth research within the above subjects, and as well as a inclusion of other subjects.

\section{Supplementary Information}

The online version contains supplementary material available at https://doi.org/10.1186/s40862-020-00105-y.

Additional file 1. Questionnaire

Additional file 2. Model Fit Summary.

\section{Abbreviations}

AE: Aviation English; ATC: Air traffic control; ATCOs: Air traffic controllers; ATM: Air traffic management; ATS: Air traffic service; CBI: Content-based instruction; CBLT: Content-Based Language Training; CVR: Content validity ratio; CVI: Content validity index; UN: United Nations; EFL: English as a foreign language; ESL: English as a second language; ESP: English for specific purposes; ICAO: International Civil Aviation Organization; IELP: ICAO English Language Proficiency; LPR: Language proficiency requirement; SEM: Structural equation model; SOP: Standard operating procedure

\section{Acknowledgements}

Not applicable.

\section{Authors' contributions}

All authors of the research had more or less equal contributions in the process of conception, design, acquisition of data, analysis and interpretation of data. They have all been involved in revising the manuscript critically to the same extent. All take public responsibility for the whole content. All are equally accountable for all aspects of the work. All authors read and approved the final manuscript.

Funding

The study did not receive any funding.

Availability of data and materials

The data will be available upon requesting.

Competing interests

The authors declare that they have no competing interests.

Received: 19 July 2020 Accepted: 1 December 2020

Published online: 04 January 2021

References

Authority, C. A. (2010). CAP 413: Radiotelephony Manual, London.

Baldursson, P. A. (2017). Technical vocabulary in aviation a study of private pilot students in Iceland. (M.A dissertation). University of Iceland Retrieved from https://skemman.is/handle/1946/27411.

Barkhordari, R. (2017). English needs analysis of Iran air airport services personnel at Isfahan airport. International Journal of Foreign Language Teaching and Research, 5(19), 79-89.

Barshi, l., \& Farris, C. (2016). Misunderstandings in ATC communication: Language, cognition, and experimental methodology. London: Routledge.

Barshi, I., \& Healy, A. F. (2002). The effects of mental representation on performance in a navigation task. Memory \& Cognition, 30(8), 1189-1203.

Bentler, P. M., \& Weeks, D. G. (1980). Linear structural equations with latent variables. Psychometrika, 45(3), 289-308. 
Bolton, L. B., \& Pan, D. (2018). Properties for formally assessing the performance level of human-human collaborative procedures with miscommunications and erroneous human behavior. International Journal of Industrial Ergonomics, 63, 75-78 Retrieved from: http://elsevier.com/locate/ergon.

Borowska, P. A. (2018). A multilingual speaker in global aviation communication. Journal of Research into Multilingualism, 1(1), $19-28$.

Brown, T. A. (2015). Confirmatory factor analysis for applied research. New York: Guilford publications.

Byrne, B. M. (2013). Structural equation modeling with Mplus: Basic concepts, applications, and programming. London: Routledge.

Cawagdan, H. C. C. C. C., \& Rivera, E. E. (2018). Influence of language learning strategies to the English proficiency test performance of college students. JPAIR Multidisciplinary Research, 32(1), 149-163.

Chermahini, S. A., Ghanbari, A., \& Talab, M. G. (2013). Learning styles and academic performance of students in English as a second-language class in Iran. Bulgarian Journal of Science and Education Policy, 7(2), 322.

Connell, L. (1996). Pilot and controller communication issues. (Report no.DOT/FAA/AM-96/10). Washington DC: Federal Aviation Administration.

Emery, H. (2014). Developments in LSP testing 30 years on? The case of aviation English. Language Assessment Quarterly, $11(2), 198-215$.

FAA Academy Airports and International Training Division, AMA-800. (2010). Performance work statement (PWS), Aviation English training.

Garcia, C. A. (2015). What do ICAO lanquage proficiency test developers and raters have to say about the ICAO lanquage proficiency requirements 12 years after their publication? (MA dissertation). Lancaster University Retrieved from: http://pesquisa.icea.gov.br/geia/artigos/garcia-2015.pdf.

Gardilcic, D. (2003). Status of English language standard for use in civil aviation. Buenos Aires: Presentation, International Civil Aviation Organization.

Gürsoy, E., \& Eken, E. (2018). English teachers' understanding of the new English language teaching program and their classroom implementations. Journal of Language and Linguistic Studies, 14(2), 18-33.

Hall, G. (2011). Exploring English language teaching: Language in action. London: Routledge, Taylor \& Francis.

Hashemyolia, S., \& Ayub, A. F. M. (2014). The effects of utilizing English language courseware on secondary school students' performance in Iran. Journal of Educational and Social Research, 4(3), 71.

Ikeda, M. (2013). Does CLIL work for Japanese secondary school students. Potential for the 'weak. Retrieved from: https://www.alttrainingonline.com/uploads/5/8/4/9/58498655/ikeda_clii_in_hs_icrj-vol21-article3.pdf.

Ikeda, M. (2016). Does CLIL work for Japanese secondary school students? Potential for the 'weak' version of CLIL. International CLIL Research Journal, 2(1), 2013.31-2013.43.

International Civil Aviation Organization (2001). Annex 11 air traffic services. Montreal: www.icao.int.

International Civil Aviation Organization (ICAO) (2004). Manual on the implementation of ICAO language proficiency requirements (Doc. 9835). Montreal: ICAO.

International Civil Aviation Organization (ICAO) (2009). Guidelines for aviation English training programmes (Cir 323). Montreal: ICAO.

International Civil Aviation Organization (ICAO) (2010). Manual on the implementation of ICAO language proficiency requirements (Doc. 9835), (2nd ed., ). Montreal: ICAO.

International Civil Aviation Organization (ICAO) (2011). Personnel Licensing (Annex 1). Montreal: ICAO.

International Civil Aviation Organization (ICAO) (2013). Manual on the English language proficiency assessment. Montreal: ICAO https://doi.org/10.1177/0265532214544394.

Khruawan, P., \& Dennis, N. K. (2017). A study of English reading comprehension using content-based instruction approach. International Journal of Research, 5(1), 368-375 https://doi.org/10.5281/zenodo.266416.

Kim, H., \& Elder, C. (2009). Understanding aviation English as a lingua franca. Australian Review of Applied Linguistics, 32(3), 1-23.

Kim, H., \& Elder, C. (2014). Interrogating the construct of aviation English: Feedback from test takers in Korea. Language Testing, Language Testing, 32(2), 129-149.

Kim, H., \& Elder, C. (2015). Interrogating the construct of aviation English: Feedback from test takers in Korea. Language Testing, 32(2), 129-149.

Kline, R. B. (2015). Principles and practice of structural equation modeling. New York: Guilford publications.

Kunstmann, A. H. (2003). A path anaylysis for factors affecting head start teachers' beliefs about inclusion. Doctoral dissertation, The Ohio State University Retrieved from: http://rave.ohiolink.edu/etdc/view?acc_num=osu1053557205.

Lawshe, C. H. (1975). A quantitative approach to content validity 1. Personnel Psychology, 28(4), 563-575.

Lebas, M. J. (1995). Performance measurement and performance management. International Journal of Production Economics, $41(1-3), 23-25$

Loehlin, J. C. (2004). Latent variable models: An introduction to factor, path, and structural equation analysis, (4th ed., ). Lawrence Erlbaum Associates Publishers.

Mäkilä, M. (2014). Measuring and managing process performance in a contemporary multinational organization: a case study. (MA dissertation). University of Aalto Retrieved from https:/aaltodoc.aalto.fi/handle/123456789/13655.

Mathews, E. (2007). The value of content-based language training for the aviation industry. ICAO Journal, 63(1) Retrieved from https://arc.aiaa.org/doi/abs/10.2514/6.2018-1399.

Mauro, R. (2018). Aviation English is Distinct from Conversational English: Evidence from Prosodic Analyses and Listening Performance This dissertation has been accepted and approved in partial fulfillment of the requirements for the Doctor of Philosophy degree in the Department of Linguistics by: Eric Pederson Chair. Eugene: Doctoral dissertation, University of Oregon.

Moder, C. (2013). Aviation English. In B. Paltridge (Ed.), The handbook of English for specific purposes. West Sussex: Wiley Blackwell.

Moder, C. L., \& Halleck, G. B. (2009). Planes, politics and oral proficiency. Australian Review of Applied Linguistics, 32(3), 25-21.

Mohebbi, H., \& Masjedlou, A. P. (2017). The challenges and reservations of planning content-based instruction in Iranian EFL setting. Journal of Teaching English for Specific and Academic Purposes, 4(3), 581-589. 
Moriyoshi, N. (2010). Content-based instruction (CBI) in Japanese college classrooms: Focusing on language, content, or both? Doctoral dissertation, McGill University Library Retrieved from http://digitool.library.mcgill.ca/thesisfile97218.pdf.

Moskalenko, O. I., \& Didenko, O. V. (2018). A computer tool for training pilots'listening skills in aviation English. Information Technologies and Learning Tools, 67(5), 187-198.

Organization, I. C (2017). Doc 10056 manual on air traffic controller competency-based training and assessment, (1st ed., ) Montreal: www.icao.int.

Pennell, S. (2017). Exploring the balance: A path analysis examination of the maintaining the balance model. Doctoral dissertation, The University of Massachusetts Retrieved from https://scholarworks.umass.edu/dissertations_2/947/.

Raykov, T., \& Marcoulides, G. A. (2012). A first course in structural equation modeling. London: Routledge.

Rothaug, J. (2004). Age, experience and automation in European air traffic control-survey in the ECAC area. Retrieved from: https://www.eurocontrol.int

Santikarn, B., \& Wichadee, S. (2018). Flipping the classroom for English language learners: A study of learning performance and perceptions. International Journal of Emerging Technologies in Learning (iJET), 13(09), 123-135.

Santos, M. G., Pacheco, V. A., Reyes, R. R., \& Vargas, G. V. (2018). Analysis of the methodology applied in aviation English course at a military school in Salinas. Journal of Education and Human Development, 7(3), 39-44.

Streiner, D. L. (2005). Finding our way: An introduction to path analysis. The Canadian Journal of Psychiatry, 50(2), 115-122.

Tajima, A. (2004). Fatal miscommunication: English in aviation safety. World Englishes, 23(3), 451-470 https://doi.org/10.1111/j. 0883-2919.2004.00368.

Trippe, J. E. (2018). Aviation English is distinct from conversational English: Evidence from prosodic analyses and listening performance. Eugene: Doctoral dissertation, University of Oregon.

Tsai, Y.-L., \& Shang, H.-F. (2010). The impact of content-based language instruction on EFL students' reading performance. Asian Social Science, 6(3), 77-84.

Waltz, C. F., \& Bausell, R. B. (1981). Nursing research: Design, statistics, and computer analysis. Lawrence: FA Davis Co.

Williams, J. G. (2016). Solutions for improving the safety of aviation communication. (MA dissertation). School of Education University of Leicester Retrieved from https://www.aviationenglishacademy.com.au/.

Zolfagharian, A. (2017). Needs analysis of aviation English for air traffic controllers. International Journal of Language Learning and Applied Linguistics World, 16(1), 54-68.

\section{Publisher's Note}

Springer Nature remains neutral with regard to jurisdictional claims in published maps and institutional affiliations.

\section{Submit your manuscript to a SpringerOpen ${ }^{\circ}$ journal and benefit from:}

- Convenient online submission

- Rigorous peer review

- Open access: articles freely available online

- High visibility within the field

- Retaining the copyright to your article

Submit your next manuscript at $\boldsymbol{\nabla}$ springeropen.com 